\title{
Paliperidone ER and oral risperidone in patients with schizophrenia: a comparative database analysis
}

\author{
Ibrahim Turkoz ${ }^{1 *}$, Cynthia A Bossie ${ }^{2}$, Jean-Pierre Lindenmayer ${ }^{3}$, Nina Schooler ${ }^{4}$, Carla M Canuso ${ }^{1}$
}

\begin{abstract}
Background: To compare the efficacy and tolerability of paliperidone extended-release (ER) with risperidone immediate-release using propensity score methodology.

Methods: Six double-blind, randomized, placebo-controlled, short-term clinical trials for acute schizophrenia with availability of individual patient-level data were identified (3 per compound). Propensity score pairwise matching was used to balance observed covariates between the paliperidone ER and risperidone patient populations. Scores were generated using logistic regression models, with age, body mass index, race, sex, baseline Positive and Negative Syndrome Scale (PANSS) total score and baseline Clinical Global Impressions-Severity (CGI-S) score as factors. The dosage range of paliperidone ER (6-12 mg/day) was compared with 2 risperidone dosage ranges: 2-4 and 4-6 mg/day. The primary efficacy measure was change in PANSS total score at week 6 end point. Tolerability end points included adverse event (AE) reports and weight. AEs with rates $\geq 5 \%$ and with $a \geq 2 \%$ difference between paliperidone ER and risperidone were identified.
\end{abstract}

Results: Completion rates for placebo-treated subjects in paliperidone ER trials $(n=95)$ and risperidone trials $(n=$ 122) groups were $36.8 \%$ and $51.6 \%$, respectively; end point changes on PANSS total scores were similar ( $p=0.768)$. Completion rates for subjects receiving paliperidone ER 6-12 mg/day $(n=179)$, risperidone $2-4 \mathrm{mg} /$ day $(n=113)$ or risperidone $4-6 \mathrm{mg} /$ day $(n=129)$ were $64.8 \%, 54.0 \%$ and $66.7 \%$, respectively (placebo-adjusted rates: paliperidone ER vs risperidone 2-4 mg/day, $p=0.005$; paliperidone ER vs risperidone $4-6 \mathrm{mg} / \mathrm{day}, \mathrm{p}=0.159$ ). PANSS total score improvement with paliperidone ER was greater than with risperidone $2-4 \mathrm{mg} /$ day (difference in mean change score, $-6.7 ; p<0.05)$ and similar to risperidone $4-6 \mathrm{mg} /$ day $(0.2 ; \mathrm{p}=0.927)$. Placebo-adjusted AEs more common with paliperidone ER were insomnia, sinus tachycardia and tachycardia; more common with risperidone were somnolence, restlessness, nausea, anxiety, salivary hypersecretion, akathisia, dizziness and nasal congestion. Weight changes with paliperidone ER and risperidone were similar (paliperidone ER vs risperidone 2-4 mg/day, $\mathrm{p}=0.489$; paliperidone ER vs risperidone $4-6 \mathrm{mg} /$ day, $\mathrm{p}=0.236$ ).

Conclusions: This indirect database analysis suggested that paliperidone ER 6-12 mg/day may be more efficacious than risperidone 2-4 mg/day and as efficacious as risperidone 4-6 mg/day. The AE-adjusted incidence rates suggest differences between treatments that may be relevant for individual patients. Additional randomized, direct, headto-head clinical trials are needed to confirm these findings.

\section{Background}

Paliperidone extended-release (ER) is an atypical antipsychotic that delivers the active metabolite of risperidone (9-hydroxyrisperidone) using OROS $^{\circledR}$ technology. This formulation minimizes drug plasma fluctuations relative to oral immediate-release risperidone and

\footnotetext{
* Correspondence: iturkoz@its.jnj.com

'Johnson \& Johnson Pharmaceutical Research and Development, LLC,

Titusville, New Jersey, USA

Full list of author information is available at the end of the article
}

eliminates the need for initial dose titration $[1,2]$. The 2 drugs also differ in that risperidone is metabolized in the liver via the cytochrome (CYP) P450 2D6 pathway, whereas this pathway is minimally involved in the metabolism of paliperidone ER. Therefore, the potential for clinically significant interactions between paliperidone ER and other drugs metabolized by the CYP P450 2D6 pathway may be minimal $[3,4]$.

The efficacy and safety of risperidone for the treatment of schizophrenia were established more than 15 years ago

\section{Biomed Central}


[5,6]. More recently, multinational placebo-controlled studies have shown paliperidone ER 3-15 mg/day to be both efficacious and safe, with discontinuation rates due to adverse events (AEs) similar to placebo [7-9]. To date, and to our best knowledge, however, no studies have been specifically designed to directly compare the efficacy of paliperidone ER and oral risperidone.

The objective of the current analysis was to perform a post hoc statistical indirect comparison of paliperidone ER and risperidone using propensity score matching. Propensity scores, originally introduced by Rosenbaum and Rubin [10], can be used to create treatment groups that are balanced on a large number of baseline characteristics; they are the observational study analogue of randomization.

\section{Methods}

\section{Analysis sets}

This comparative analysis pooled double-blind, randomized, placebo-controlled, short-term (4- to 8-week) clinical studies of paliperidone ER or risperidone monotherapy in acutely ill adults with schizophrenia aged 18-65 inclusive, in which detailed patient-level data were available. A total of 6 studies were identified: 3 for paliperidone ER and 3 for risperidone (Table 1). A literature search (through December 31, 2009) confirmed that these 6 studies were the only studies that met the inclusion criteria and had individual patient-level data that were available. In the risperidone studies (conducted between 1988 and 1996), prior antipsychotic treatment consisted primarily of conventional agents, whereas in the paliperidone ER studies (conducted between 2004 and 2005), over $50 \%$ of subjects had received prior treatment with atypical antipsychotics. Therefore, subjects from the paliperidone ER trials were included only if they had received conventional antipsychotics within 90 days before the start of the study, regardless of concomitant use of other agents, including atypical antipsychotics. All subjects in risperidone studies RIS-USA-1 and RIS-INT-3 were included, and RIS-USA-72 subjects were included if they did not take atypical antipsychotics prior to the study (clozapine and risperidone were available at the time of this study). DSM-III-R/IV diagnosis codes for inclusion were 295.10, 295.20, 295.30, 295.60 or 295.90. Exclusions were age $>65$ years and risperidone $>8 \mathrm{mg} /$ day. Because the RIS-USA-1 trial had a flexible-dosing regimen, subjects were assigned to a dose group based on their modal dose. Defined treatment groups were paliperidone ER 6-12 mg/day, risperidone $2-4 \mathrm{mg} /$ day, risperidone $4-6 \mathrm{mg} /$ day or placebo. Since the studies were conducted during different decades, the above inclusion and exclusion criteria for this analysis were chosen to minimize differences between the populations.
Paliperidone ER in the dose range 6-12 $\mathrm{mg} /$ day was chosen for comparison because it is likely to provide a favorable risk/benefit for most patients with schizophrenia. (The recommended range is 3-12 mg/day.) Based on pharmacokinetic data, paliperidone $6-12 \mathrm{mg} /$ day and risperidone $2-4 \mathrm{mg} /$ day were compared because they were expected to provide similar systemic drug exposure [2]. Paliperidone ER 6-12 mg/day was also compared with risperidone 4-6 $\mathrm{mg} /$ day as these dose ranges were expected to yield the most favorable risk/benefit ratios based on clinical data. The placebo groups of the risperidone and paliperidone ER trials were referred to as placebo (risperidone [RIS]) and placebo (paliperidone ER [PALI]). They were pooled for some analyses as described below.

\section{Efficacy and safety outcomes}

Efficacy endpoints included change in the Positive and Negative Syndrome Scale (PANSS) total (primary efficacy measure) [11] and factor scores [12] (for all studies excluding RIS-USA-1), Clinical Global ImpressionsSeverity (CGI-S) score [13] (for all studies excluding RIS-USA-72), response rates ( $\geq 30 \%$ decrease in total PANSS score from baseline), weight and spontaneously reported AEs. Owing to differences in AE coding between programs, 2 clinicians reviewed all AEs in a blinded fashion to map verbatim terms to preferred terms; these were then mapped to a System Organ Class (SOC) using MedDRA (Medical Dictionary for Regulatory Activities) terminology. Extrapyramidal symptoms (EPS) measures were not included due to the difference in rating scales between the risperidone (Extrapyramidal Symptoms Rating Scale) and paliperidone (Simpson Angus Scale) studies.

\section{Statistical analysis \\ Propensity score matching}

In the present analysis, propensity score matching was used to create comparison groups that were similar with respect to the distribution of a number of demographic and baseline characteristics so that indirect comparisons would be more valid. A propensity score for each patient was created using variables common to both sets of studies from multiple logistic regression models. Subjects were matched as stringently as possible while maintaining sufficient patient numbers for analysis. A 1to-many matching scheme with a caliper (distance) of 0.05 was used to match each treated subject with the closest control. In 1-to-many matching, all cases are initially matched to their "best" control in the first iteration, and "next best" matches next in hierarchical sequence until no more matches can be made. Best matches are those with the smallest difference in propensity scores. Goodness of matches and available 
Table 1 Randomized placebo-controlled studies available for analysis

\begin{tabular}{|c|c|c|c|c|c|c|}
\hline \multicolumn{7}{|c|}{ Paliperidone ER } \\
\hline $\begin{array}{c}\text { Study } \\
\text { (Year } \\
\text { Completed) }\end{array}$ & $\mathrm{N}^{*}$ & Population & Dose (mg/day) & $\begin{array}{l}\text { Duration } \\
\text { (Weeks) }\end{array}$ & $\begin{array}{l}\text { Efficacy } \\
\text { Measures }\end{array}$ & Safety Measures \\
\hline $\begin{array}{l}\text { PALI-SCH-303 } \\
\text { (2005) [7] }\end{array}$ & $500^{\dagger}$ & $\begin{array}{l}\text { - Patients with schizophrenia, diagnosis for } \geq 1 \mathrm{yr} \\
\text { - Agreed to hospitalization for at least the first } 14 \\
\text { days of the study } \\
\text { - Acute episode with PANSS total score 70-120 }\end{array}$ & $6,9,12(\mathrm{qd})$ & 6 & PANSS, CGI & $\begin{array}{l}\text { SAS, BARS, AIMS, } \\
\text { AEs, labs, weight }\end{array}$ \\
\hline $\begin{array}{c}\text { PALI-SCH-304 } \\
\text { (2004) [8] }\end{array}$ & $327^{\dagger}$ & $\begin{array}{l}\text { - Patients with schizophrenia, diagnosis for } \geq 1 \mathrm{yr} \\
\text { - Agreed to hospitalization for at least the first } 14 \\
\text { days of the study } \\
\text { - Acute episode with PANSS total score } 70-120\end{array}$ & $6,12(q d)$ & 6 & PANSS, CGI & $\begin{array}{l}\text { SAS, BARS, AIMS, } \\
\text { AEs, labs, weight }\end{array}$ \\
\hline $\begin{array}{l}\text { PALI-SCH-305 } \\
(2005) \\
{[9]}\end{array}$ & $366^{+}$ & $\begin{array}{l}\text { - Patients with schizophrenia, diagnosis for } \geq 1 \mathrm{yr} \\
\text { - Agreed to hospitalization for at least the first } 14 \\
\text { days of the study } \\
\text { - Acute episode with PANSS total score } 70-120\end{array}$ & $3,9,15$ (qd) & 6 & PANSS, CGI & $\begin{array}{l}\text { SAS, BARS, AIMS, } \\
\text { AEs, labs, weight }\end{array}$ \\
\hline \multicolumn{7}{|c|}{ Risperidone } \\
\hline Study & $\mathbf{N}$ & Population & Dose (mg/day) & $\begin{array}{l}\text { Duration } \\
\text { (Weeks) }\end{array}$ & $\begin{array}{l}\text { Efficacy } \\
\text { Measures }\end{array}$ & Safety Measures \\
\hline RIS-USA-1 $(1990)^{\ddagger}$ & 160 & $\begin{array}{l}\text { - Patients with schizophrenia } \\
\text { - Inpatients at the start of the study } \\
\text { - Minimum BPRS score of } 30 \text {, with a minimum } \\
\text { score of at least moderate (4) on } 2 \text { of the } \\
\text { following items: conceptual disorganization, } \\
\text { suspiciousness, hallucinatory behavior, unusual } \\
\text { thought content }\end{array}$ & $1-10^{\S}(\mathrm{qd})$ & 6 & BPRS, CGI & $\begin{array}{l}\text { ESRS, AIMS, AEs, } \\
\text { labs, weight }\end{array}$ \\
\hline $\begin{array}{c}\text { RIS-INT-3 (1991) } \\
\text { [5]; [6] }\end{array}$ & 523 & $\begin{array}{l}\text { - Patients with chronic schizophrenia } \\
\text { - Inpatients at the start of the study } \\
\text { - PANSS total score } 60-120\end{array}$ & $2,6,10,16$ (bid) & 8 & PANSS, CGI & $\begin{array}{c}\text { ESRS, AEs, labs, } \\
\text { weight }\end{array}$ \\
\hline RIS-USA-72 (1996) $)^{\ddagger}$ & 246 & $\begin{array}{l}\text { - Patients with schizophrenia } \\
\text { - Inpatients at the start of the study } \\
\text { - PANSS total score } 80-120 \text {, with a PANSS score } \\
\geq 8 \text { for the sum of } 2 \text { of the following items: } \\
\text { conceptual disorganization, suspiciousness, } \\
\text { hallucinatory behavior, unusual thought content }\end{array}$ & 4,8 (qd) & 4 & PANSS & $\begin{array}{c}\text { ESRS, AEs, labs, } \\
\text { weight }\end{array}$ \\
\hline
\end{tabular}

*Intent-to-treat population.

${ }^{\dagger} \mathrm{N}$ values represent subjects who received the recommend dose of paliperidone ER (3-12 mg/day) or placebo.

‡Data on file.

${ }^{\S}$ Flexible dosing.

PANSS = Positive and Negative Syndrome Scale; CGI = Clinical Global Impressions; SAS = Simpson-Angus Scale; BARS = Barnes Akathisia Rating Scale; AIMS = Abnormal Involuntary Movement Scale; AEs = adverse events; BPRS = Brief Psychiatric Rating Scale; ESRS = Extrapyramidal Symptoms Rating Scale.

sample sizes were evaluated to determine the matching algorithm used to create a new analysis population.

Based on the selected population of 933 subjects from 6 placebo-controlled trials, matched cohorts were created by 1) pairing risperidone (regardless of dose) and its corresponding placebo group (placebo [RIS]) and 2) pairing paliperidone ER (regardless of dose) and its corresponding placebo group (placebo [PALI]). This was followed by pairing from the resulting risperidone and paliperidone ER groups identified in steps 1 and 2. All subjects in the matched risperidone/paliperidone ER group were included in the final sample. The placebo groups identified in the pairing with risperidone or paliperidone ER were then compared to confirm whether they could be combined into a pooled placebo group for efficacy analyses. This provided 3 groups (risperidone, paliperidone ER and placebo) for the efficacy comparisons. The dependent variable of the multiple logistic regression models was treatment group, and the independent variables were age, sex, race (white vs all other), baseline body mass index (BMI), baseline CGI and baseline PANSS. Choice of the independent variables was based on clinical relevance and their inclusion in all 6 studies.

\section{Analysis methods}

The primary comparisons were between paliperidone ER 6-12 $\mathrm{mg} /$ day and each dose range of risperidone. Changes from baseline to end point (week 4 in RIS-USA-72, week 8 in RIS-INT-3 and week 6 for all other studies) were evaluated using the last-observation-carried-forward (LOCF) approach. Comparisons were calculated from analysis-of-covariance models, with treatment as the between group factor and baseline as the covariate. Categorical variables and response rates at end point were 
evaluated using a chi-square test. No adjustments for multiple comparisons were made. Data were analyzed using SAS ${ }^{\circledR}$ (Version 9.1 for Windows).

Differences between placebo groups were examined, and placebo-adjusted rates were reported for those that were significant (as was the case for completion and $\mathrm{AE}$ rates). For adjusting $\mathrm{AE}$ rates, placebo corrections were applied to each active group (ie, active $\%$ - corresponding placebo \%) according to the equation: ([risperidone \% placebo (RIS) \%] - [paliperidone ER \% - placebo (PALI) $\%]$ ). If the placebo rate for any $\mathrm{AE}$ was higher than for active treatment, active treatment minus placebo was set equal to 0. Differences in AEs between paliperidone ER and risperidone were noted when the $\mathrm{AE}$ differential was $\geq 2 \%$ after correcting for the placebo rates.

\section{Results}

Data were available from 2626 subjects in the 6 studies; of these, 933 subjects were retained in the propensity score-matched population (Figure 1). A total of 179 subjects received paliperidone ER 6-12 mg/day, 113 subjects received risperidone $2-4 \mathrm{mg} /$ day, 129 subjects received risperidone 4-6 $\mathrm{mg} /$ day, 95 received placebo in paliperidone studies (placebo [PALI]) and 122 received placebo in risperidone studies (placebo [RIS]). Study completion rates for the 2 placebo groups were $36.8 \%$ with placebo (PALI) and $51.6 \%$ with placebo (RIS) ( $\mathrm{p}=$ 0.030) (Figure 1). Risperidone subjects receiving $4 \mathrm{mg} /$ day $(\mathrm{n}=63)$ were included in both risperidone groups. A comparison of the placebo (PALI) and placebo (RIS) groups for the purposes of validating the selection criteria used to match the populations indicated that baseline demographic and clinical characteristics, and betweengroup differences at end point on PANSS total and factor change scores (all p values $>0.05$ ), were similar (Table 2). Therefore, the placebo groups were pooled $(n=217)$ for further efficacy analyses.

\section{Comparison of paliperidone ER and risperidone groups}

Baseline demographic and clinical characteristics in the paliperidone ER and risperidone dose groups were comparable, as expected, because of propensity score matching (Table 3). Completion rates were $64.8 \%$ with paliperidone ER 6-12 mg/day, 54.0\% with risperidone $2-4 \mathrm{mg} /$ day and $66.7 \%$ with risperidone $4-6 \mathrm{mg} /$ day. Placebo-adjusted rates were $28.0 \%, 2.4 \%$ and $15.1 \%$ in the paliperidone ER,

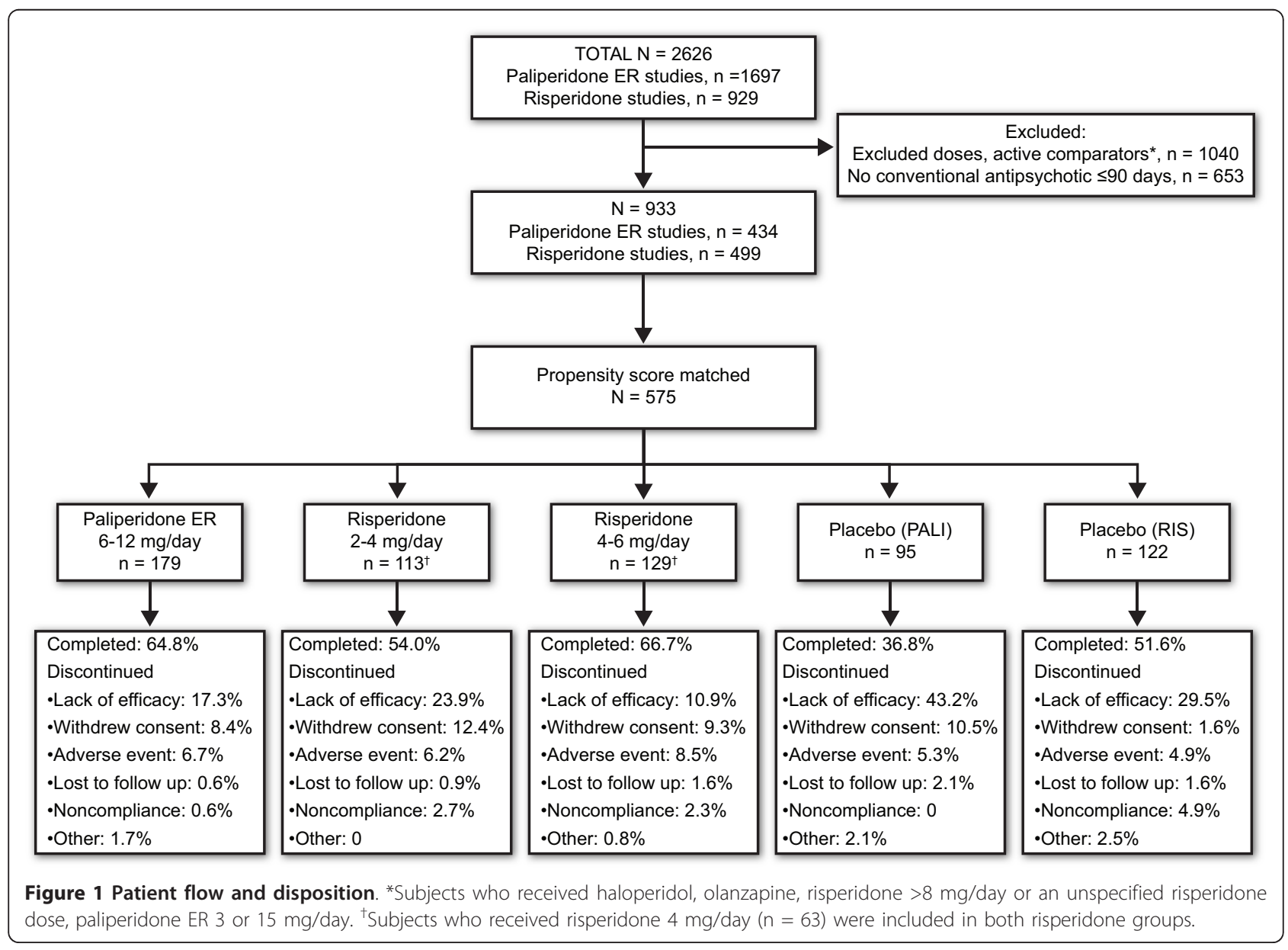


Table 2 Baseline parameters and efficacy outcomes in placebo groups from paliperidone ER and risperidone studies

\begin{tabular}{|c|c|c|c|}
\hline $\begin{array}{l}\text { Baseline Demographic and Clinical } \\
\text { Characteristics }\end{array}$ & $\begin{array}{c}\text { Placebo } \\
\text { (PALI) } \\
\mathrm{n}=95\end{array}$ & $\begin{array}{c}\text { Placebo } \\
\text { (RIS) } \\
n=122 \\
\end{array}$ & $\begin{array}{c}\mathrm{p} \\
\text { Value }\end{array}$ \\
\hline Age, years, mean (SD) & $\begin{array}{c}36.7 \\
(10.9) \\
\end{array}$ & $\begin{array}{c}38.0 \\
(10.1)\end{array}$ & 0.338 \\
\hline Female, n (\%) & $\begin{array}{c}23 \\
(24.2)\end{array}$ & $\begin{array}{c}18 \\
(14.8)\end{array}$ & 0.083 \\
\hline \multicolumn{4}{|l|}{ Race, n (\%) } \\
\hline Caucasian & $\begin{array}{c}65 \\
(91.6)\end{array}$ & $\begin{array}{c}73 \\
(93.6)\end{array}$ & 0.758 \\
\hline Other & $6(8.5)$ & $5(6.4)$ & \\
\hline BMl, mean (SD), kg/m² & $\begin{array}{l}24.9 \\
(5.2)\end{array}$ & $\begin{array}{l}25.3 \\
(3.2)\end{array}$ & 0.538 \\
\hline PANSS total score, mean (SD) & $\begin{array}{c}94.5 \\
(12.2)\end{array}$ & $\begin{array}{c}92.6 \\
(12.3)\end{array}$ & 0.254 \\
\hline CGI-S, score (SD) & $4.6(0.7)$ & $4.7(0.8)$ & 0.105 \\
\hline $\begin{array}{l}\text { PANSS, Adjusted Mean Change (SE) } \\
\text { at End Point }\end{array}$ & $\begin{array}{c}\text { Placebo } \\
\text { (PALI) } \\
\mathrm{n}=92\end{array}$ & $\begin{array}{c}\text { Placebo } \\
\text { (RIS) } \\
n=94\end{array}$ & $\begin{array}{c}\mathrm{p} \\
\text { Value }\end{array}$ \\
\hline Total score & $-6.5(2.5)$ & $-5.4(2.5)$ & 0.768 \\
\hline \multicolumn{4}{|l|}{ Factor score } \\
\hline Negative & $-1.3(0.7)$ & $-2.3(0.7)$ & 0.280 \\
\hline Positive & $-2.5(0.8)$ & $-1.6(0.8)$ & 0.423 \\
\hline Anxiety/depression & $-1.3(0.4)$ & $-1.8(0.4)$ & 0.402 \\
\hline Disorganized thoughts & $-1.2(0.6)$ & $-0.6(0.6)$ & 0.507 \\
\hline Uncontrolled hostility/excitement & $0.4(0.5)$ & $0.9(0.5)$ & 0.530 \\
\hline
\end{tabular}

$\mathrm{PALI}=$ paliperidone $\mathrm{ER} ; \mathrm{RIS}=$ risperidone; $\mathrm{BMI}=$ body mass index; PANSS = Positive and Negative Syndrome Scale; CGI-S = Clinical Global ImpressionsSeverity.

$p$ values are from ANOVA models with factor treatment for continuous variables and chi-square test for categorical variables.

risperidone 2-4 $\mathrm{mg} /$ day and risperidone 4-6 mg/day groups, respectively (placebo-adjusted $\mathrm{p}$ values for paliperidone ER vs risperidone $2-4 \mathrm{mg} /$ day, $\mathrm{p}=0.005$; paliperidone $\mathrm{ER}$ vs risperidone 4-6 mg/day, $\mathrm{p}=0.159$ ) (Figure 1 ).

\section{Comparison of paliperidone ER 6-12 mg/day and risperidone $2-4 \mathrm{mg} / \mathrm{day}$}

Paliperidone ER showed greater improvement at end point on the mean PANSS total score compared with risperidone $2-4 \mathrm{mg} /$ day (difference in mean change score, -6.7; $\mathrm{p}<0.05$ ), and more improvement on the PANSS factor scores for negative symptoms (difference in mean change score, $-2.1 ; \mathrm{p}<0.05$ ) (Table 4). Paliperidone ER, but not risperidone $2-4 \mathrm{mg} /$ day, was superior to combined placebo on the PANSS total score and factor scores for negative symptoms, anxiety/depression and disorganized thoughts $(\mathrm{p}<0.05$ for all comparisons of paliperidone ER vs placebo). A similar pattern was observed with the CGI-S score; improvement was greater with paliperidone ER than risperidone $2-4 \mathrm{mg} /$ day ( $\mathrm{p}<0.001)$ or combined placebo, but not with risperidone $2-4 \mathrm{mg} /$ day vs combined placebo (Table 4 ). The percentage of subjects who achieved a response ( $\geq 30 \%$ decrease in total PANSS score from baseline) was $55.1 \%$ with paliperidone ER vs $40.7 \%$ with risperidone $2-4 \mathrm{mg} /$ day $(\mathrm{p}<0.05)$. Response rates with paliperidone ER and risperidone $2-4 \mathrm{mg} /$ day were both significantly higher than with combined placebo (Table 4).

\section{Comparison of paliperidone ER 6-12 mg/day and risperidone 4-6 $\mathrm{mg} /$ day}

Changes in mean PANSS total score and all factor scores did not differ significantly (all between-group $\mathrm{p}$ values $>0.05$ ); both paliperidone ER and risperidone 4-6 $\mathrm{mg} /$ day were superior to combined placebo on these measures (all p values vs placebo $<0.05$ ). Improvement on the CGI-S scale was greater with paliperidone ER than risperidone 4-6 mg/day $(\mathrm{p}<0.05)$; paliperidone ER, but not risperidone 4-6 mg/day, was superior to combined placebo $(\mathrm{p}<0.001)$. Response rates with paliperidone ER and risperidone 4-6 mg/day were comparable, and rates with both active treatments were higher than

Table 3 Baseline characteristics in the propensity score-matched paliperidone ER, risperidone and pooled placebo groups

\begin{tabular}{|c|c|c|c|c|}
\hline & $\begin{array}{c}\text { Paliperidone ER } \\
6-12 \mathrm{mg} / \text { day } \\
\mathrm{n}=179\end{array}$ & $\begin{array}{c}\text { Risperidone } \\
2-4 \mathrm{mg} / \text { day } \\
\mathrm{n}=113\end{array}$ & $\begin{array}{c}\text { Risperidone } \\
4-6 \mathrm{mg} / \text { day } \\
\mathrm{n}=129\end{array}$ & $\begin{array}{c}\text { Pooled Placebo } \\
n=217\end{array}$ \\
\hline Age, years, mean (SD) & $37.4(11.3)$ & $37.8(10.6)$ & $37.1(10.1)$ & $37.4(10.4)$ \\
\hline Female, n (\%) & $45(25.1)$ & $31(27.4)$ & $32(24.8)$ & $41(18.9)$ \\
\hline \multicolumn{5}{|l|}{ Race, n (\%) } \\
\hline Caucasian & $136(76.0)$ & $83(73.5)$ & $99(76.7)$ & $138(63.6)$ \\
\hline Other & $43(24.0)$ & $30(26.5)$ & $30(23.3)$ & 79 (36.4) \\
\hline BMl, mean (SD), $\mathrm{kg} / \mathrm{m}^{2}$ & $25.2(4.7)$ & $25.5(3.3)$ & $25.5(3.4)$ & $25.1(4.2)$ \\
\hline PANSS total score, mean (SD) & $94.3(11.9)$ & $94.4(15.2)$ & $96.2(16.6)$ & $93.4(12.2)$ \\
\hline CGI-S score, mean (SD) & $4.8(0.7)$ & $4.8(0.6)$ & $4.8(0.7)$ & $4.7(0.8)$ \\
\hline
\end{tabular}

BMI = body mass index; PANSS = Positive and Negative Syndrome Scale; CGI-S = Clinical Global Impressions-Severity.

All the $p$ values are $>0.05$ for the group comparisons. $p$ values are from ANOVA models with factor treatment for continuous variables and chi-square test for categorical variables. 
Table 4 Efficacy findings for paliperidone ER and risperidone dose groups (change from baseline to end point)

\begin{tabular}{|c|c|c|c|c|}
\hline & $\begin{array}{c}\text { Paliperidone ER } \\
6-12 \mathrm{mg} / \mathrm{day} \\
\mathrm{n}=179\end{array}$ & $\begin{array}{c}\text { Risperidone } \\
2-4 \mathrm{mg} / \text { day } \\
\mathrm{n}=113\end{array}$ & $\begin{array}{c}\text { Risperidone } \\
4-6 \mathrm{mg} / \text { day } \\
\mathrm{n}=126^{*}\end{array}$ & $\begin{array}{c}\text { Pooled Placebo } \\
n=186^{*}\end{array}$ \\
\hline \multicolumn{5}{|l|}{ PANSS } \\
\hline Total score, adjusted mean change (SE) & $-18.4(1.7)$ & $-11.6(2.2)$ & $-18.7(2.0)$ & $-6.4(1.7)$ \\
\hline \multicolumn{5}{|l|}{ Mean difference (estimated SE) ${ }^{\dagger}$} \\
\hline Active-PBO & $-12.0(2.4)^{\ddagger}$ & $-5.4(2.8)$ & $-12.0(2.6)^{\ddagger}$ & NA \\
\hline PALI-RIS 2-4 mg & $-6.7(2.8)^{\S}$ & NA & NA & NA \\
\hline PALI-RIS 4-6 mg & $0.2(2.6)$ & NA & NA & NA \\
\hline Negative factor, adjusted mean change (SE) & $-4.7(0.5)$ & $-2.5(0.6)$ & $-3.8(0.5)$ & $-2.1(0.4)$ \\
\hline \multicolumn{5}{|l|}{ Mean difference (estimated SE) ${ }^{\dagger}$} \\
\hline Active-PBO & $-2.6(0.6)^{\ddagger}$ & $-0.5(0.8)$ & $-1.7(0.7)^{\S}$ & NA \\
\hline PALI-RIS 2-4 mg & $-2.1(0.8)^{\S}$ & NA & NA & NA \\
\hline PALI-RIS 4-6 mg & $-0.9(0.7)$ & NA & NA & NA \\
\hline Positive factor, adjusted mean change (SE) & $-6.2(0.5)$ & $-4.5(0.7)$ & $-6.3(0.7)$ & $-2.3(0.5)$ \\
\hline \multicolumn{5}{|l|}{ Mean difference (estimated SE) ${ }^{\dagger}$} \\
\hline Active-PBO & $-4.0(0.8)^{\ddagger}$ & $-2.2(0.9)^{\S}$ & $-4.1(0.8)^{\ddagger}$ & NA \\
\hline PALI-RIS 2-4 mg & $-1.7(0.9)$ & NA & NA & NA \\
\hline PALI-RIS 4-6 mg & $0.1(0.8)$ & NA & NA & NA \\
\hline Anxiety/depression, adjusted mean change (SE) & $-2.3(0.3)$ & $-1.7(0.3)$ & $-2.5(0.3)$ & $-1.4(0.3)$ \\
\hline \multicolumn{5}{|l|}{ Mean difference (estimated SE) ${ }^{\dagger}$} \\
\hline Active-PBO & $-0.9(0.4)^{\S}$ & $-0.3(0.4)$ & $-1.1(0.4)^{\S}$ & NA \\
\hline PALI-RIS 2-4 mg & $-0.6(0.4)$ & NA & NA & NA \\
\hline PALI-RIS 4-6 mg & $0.2(0.4)$ & NA & NA & NA \\
\hline Disorganized thoughts, adjusted mean change (SE) & $-3.5(0.4)$ & $-2.3(0.5)$ & $-4.2(0.5)$ & $-1.1(0.4)$ \\
\hline \multicolumn{5}{|l|}{ Mean difference (estimated SE) ${ }^{\dagger}$} \\
\hline Active-PBO & $-2.4(0.6)^{\ddagger}$ & $-1.3(0.7)$ & $-3.2(0.7)^{\ddagger}$ & NA \\
\hline PALI-RIS 2-4 mg & $-1.1(0.7)$ & NA & NA & NA \\
\hline PALI-RIS 4-6 mg & $0.8(0.7)$ & NA & NA & NA \\
\hline Uncontrolled hostility/excitement, adjusted mean change (SE) & $-1.4(0.3)$ & $-0.6(0.4)$ & $-2.0(0.4)$ & $0.6(0.3)$ \\
\hline \multicolumn{5}{|l|}{ Mean difference (estimated SE) ${ }^{\dagger}$} \\
\hline Active-PBO & $-2.0(0.5)^{\ddagger}$ & $-1.2(0.5)^{\S}$ & $2.6(0.5)^{\ddagger}$ & NA \\
\hline PALI-RIS 2-4 mg & $-0.8(0.5)$ & NA & NA & NA \\
\hline PALI-RIS 4-6 mg & $0.6(0.5)$ & NA & NA & NA \\
\hline CGI-S, adjusted mean change (SE)" & $-0.9(0.1)$ & $0.0(0.2)$ & $-0.1(0.2)$ & $-0.2(0.1)$ \\
\hline \multicolumn{5}{|l|}{ Mean difference (estimated SE) ${ }^{\dagger}$} \\
\hline Active-PBO & $-0.7(0.1)^{\ddagger}$ & $0.2(0.2)$ & $0.0(0.3)$ & NA \\
\hline PALI-RIS 2-4 mg & $-0.9(0.2)^{\ddagger}$ & NA & NA & NA \\
\hline PALI-RIS 4-6 mg & $-0.8(0.3)^{\S}$ & NA & NA & NA \\
\hline Response, $\%^{\#}$ & 55.1 & 40.7 & 51.6 & 28.1 \\
\hline Active-PBO & $26.9^{\S}$ & $28.5^{\S}$ & $23.4^{\S}$ & NA \\
\hline PALI-RIS 2-4 mg & $14.4^{\S}$ & NA & NA & NA \\
\hline PALI-RIS 4-6 mg & 3.5 & NA & NA & NA \\
\hline
\end{tabular}

Separate models were run for comparison of risperidone 2-4 mg/day and risperidone 4-6 mg/day against paliperidone ER 6-12 mg/day and pooled placebo groups. Adjusted means for the pooled placebo group are presented from the model comparing paliperidone ER with risperidone 4-6 mg/day. Data are nearly identical to those for the model comparing paliperidone ER with risperidone $2-4 \mathrm{mg} /$ day. $\mathrm{p}$ values are from ANCOVA models with factor treatment and covariate baseline score for continuous variables and chi-square test for categorical variables.

*Not all subjects had a PANSS assessment.

${ }^{\dagger} \mathrm{A}$ negative sign indicates greater improvement vs comparator.

${ }^{\ddagger} \mathrm{p}<0.0001 ;{ }^{\mathrm{s}} \mathrm{p}<0.05$.

${ }^{9}$ Numbers of subjects assessed were 179, 53, 69 and 167 for the paliperidone ER, risperidone 2-4 mg/day, risperidone 4-6 mg/day and pooled placebo groups, respectively.

"Response was defined as $\geq 30 \%$ decrease in total PANSS score from baseline.

PANSS = Positive and Negative Syndrome Scale; PALI = paliperidone ER; RIS = risperidone PBO = placebo; CGI-S = Clinical Global Impressions-Severity; $\mathrm{NA}=$ not applicable. 
with combined placebo $(\mathrm{p}<0.001$ for both active treatments vs combined placebo) (Table 4).

\section{Safety}

No statistical tests were applied to AE data, but placebo corrections were applied to each active group as described in the Methods section. Placebo-adjusted AE rates that differed by $\geq 2 \%$ between groups are presented (Table 5). For the paliperidone ER vs risperidone 2-4 mg comparison, placebo-adjusted AEs more common with paliperidone ER than risperidone were sinus tachycardia and tachycardia; placebo-adjusted AEs more common with risperidone than paliperidone ER were somnolence, restlessness, nausea, anxiety, salivary hypersecretion and akathisia (Table 5). For paliperidone ER vs risperidone 4-6 mg, placebo-adjusted AEs more common with paliperidone ER than risperidone included insomnia and sinus tachycardia; placebo-adjusted AEs more common with risperidone than paliperidone ER were somnolence, restlessness, nausea, anxiety, salivary hypersecretion, akathisia, nasal congestion and dizziness (Table 5).

Weight change was significantly greater with paliperidone ER, risperidone 2-4 mg/day and risperidone 4-6 mg/ day than with placebo (all p values $<0.001$ ), but was not significantly different among the active-treatment groups. Adjusted mean change (SE): paliperidone ER, 0.7 (0.3) kg; risperidone $2-4 \mathrm{mg} /$ day, $1.0(0.4) \mathrm{kg}$; and risperidone 4-6 mg/day, $1.3(0.4) \mathrm{kg}$ (paliperidone ER vs risperidone 2-4 mg/day, $\mathrm{p}=0.487$; vs risperidone 4-6 mg/day, $\mathrm{p}=0.235$ ).

\section{Discussion}

This analysis used propensity score matching of subjects from randomized placebo-controlled schizophrenia studies to compare paliperidone ER 6-12 mg/day with risperidone 2-4 $\mathrm{mg} / \mathrm{day}$ and risperidone 4-6 $\mathrm{mg} /$ day. Although the approved dose range of paliperidone ER is 3-12 $\mathrm{mg} /$ day, this analysis focused on 6-12 $\mathrm{mg} /$ day because comparisons between paliperidone ER 6-12 mg/ day and risperidone $2-4 \mathrm{mg} /$ day were expected to provide similar systemic drug exposure based on pharmacokinetic data [2]. Comparisons between paliperidone ER 6-12 mg/day and risperidone 4-6 mg/day were performed as these dose ranges were expected to yield the most favorable risk/benefit ratios based on clinical data.

The significant difference in the mean PANSS total scores suggested that paliperidone ER 6-12 mg/day may be more efficacious than risperidone $2-4 \mathrm{mg} / \mathrm{day}$. Consistent results were observed on PANSS factor scores, CGI-S scores, response rates and placebo-corrected discontinuation rates for lack of efficacy. Data further suggested that paliperidone ER 6-12 mg/day achieved good overall tolerability compared with risperidone $2-4 \mathrm{mg} /$ day, except for increased rates for tachycardia and sinus tachycardia. Discontinuation rates due to AEs were comparable, and weight gain for the 2 groups was similar.

Changes in the mean PANSS total score suggested that paliperidone ER 6-12 $\mathrm{mg} /$ day may be similar to risperidone 4-6 mg/day in terms of efficacy. This result is consistent with PANSS factor score and response rate data; however, overall clinical status (CGI-S) improved significantly more with paliperidone ER. Also, these data suggest that with the exception of increased rates of insomnia and tachycardia, paliperidone ER 6-12 mg/day achieved good overall tolerability compared with risperidone 4-6 mg/day.

Because there is no control over treatment assignments, covariate differences between groups may lead to biased estimates of treatment effects, as treatment groups may not be comparable. The advantage of propensity score matching is that observed covariates between groups can be balanced, thereby reducing selection bias for treatment assignment [14]. Further, this analysis used individual rather than group data, offering advantages over meta-analytic techniques such as the ability to identify the exact populations to be studied and to have access to individual data points. Notably, although studies were conducted at different times and in different countries, no significant differences were found in baseline-to-end point change on any efficacy measure between the placebo groups from the paliperidone ER and risperidone studies, suggesting that identification of analysis populations using this approach was viable for comparing paliperidone ER and risperidone.

However, propensity score analyses have several limitations. First, because this analysis relies on clinical trial databases, differences in trial design between the paliperidone ER and risperidone studies may have introduced additional bias in estimating treatment differences. The shorter duration of RIS-USA-72 (4 weeks vs 6-8 weeks for all other studies) (Table 1) could have introduced a bias favoring risperidone, particularly with regard to completion rates and $\mathrm{AE}$ reports. Further, entry into open-label extensions of the paliperidone ER studies was permitted at week 3 ; in the RIS-INT-3 risperidone study, however, subjects could enter the openlabel extension only if they completed the double-blind phase. This difference could have introduced a bias for completing the risperidone study. At the time the risperidone studies were conducted, regulations limited inclusion of women in phase III clinical trials, resulting in marked differences in the percentages of women included in the risperidone and paliperidone studies. Additionally, as patient-level data are necessary to perform propensity score analyses, this method can only be used if individual patient-level data are available. 
Table 5 Treatment-emergent adverse events in $\geq 5 \%$ in any active-treatment or placebo groups

\begin{tabular}{|c|c|c|c|c|c|c|c|}
\hline & \multirow[b]{2}{*}{$\begin{array}{c}\text { Paliperidone } \\
\text { ER } \\
6-12 \mathrm{mg} / \text { day } \\
n=179 \\
n(\%)\end{array}$} & \multirow[b]{2}{*}{$\begin{array}{c}\text { Placebo } \\
\text { (PALI) } \\
\mathrm{n}=95 \\
\mathrm{n}(\%)\end{array}$} & \multirow[b]{2}{*}{$\begin{array}{c}\text { Risperidone } \\
2-4 \mathrm{mg} / \text { day } \\
\mathrm{n}=113 \\
\mathrm{n}(\%)\end{array}$} & \multirow[b]{2}{*}{$\begin{array}{c}\text { Risperidone } \\
4-6 \text { mg/day } \\
n=129 \\
n(\%)\end{array}$} & \multirow[b]{2}{*}{$\begin{array}{c}\text { Placebo } \\
\text { (RIS) } \\
n=122 \\
n(\%)\end{array}$} & \multicolumn{2}{|c|}{$\begin{array}{l}\text { Placebo-Adjusted } \\
\text { Difference }{ }^{*} \geq 2 \%\end{array}$} \\
\hline & & & & & & $\begin{array}{c}\text { Paliperidone ER } 6-12 \mathrm{mg} / \text { day } \\
\text { vs Risperidone } \\
2-4 \mathrm{mg} / \text { day }\end{array}$ & $\begin{array}{c}\text { Paliperidone ER 6-12 mg/ } \\
\text { day vs Risperidone } \\
4-6 \mathrm{mg} / \text { day }\end{array}$ \\
\hline \multicolumn{8}{|c|}{ Placebo-Adjusted AEs More Common With Paliperidone ER Than Risperidone } \\
\hline Insomnia & $26(14.5)$ & $9(9.5)$ & $25(22.1)$ & $22(17.1)$ & $\begin{array}{c}23 \\
(18.9)\end{array}$ & $N A^{\dagger}$ & 5.0 \\
\hline $\begin{array}{l}\text { Sinus } \\
\text { tachycardia }\end{array}$ & $14(7.8)$ & $4(4.2)$ & $1(0.9)$ & $2(1.6)$ & $0(0.0)$ & 2.7 & 2.0 \\
\hline Tachycardia & $12(6.7)$ & $3(3.2)$ & $1(0.9)$ & $3(2.3)$ & $0(0.0)$ & 2.6 & $\mathrm{NA}^{+}$ \\
\hline \multicolumn{8}{|c|}{ Placebo-Adjusted AEs More Common With Risperidone Than Paliperidone ER } \\
\hline Somnolence & $7(3.9)$ & $5(5.3)$ & $10(8.9)$ & $9(7.0)$ & $2(1.6)$ & 7.3 & 5.4 \\
\hline Restlessness & $0(0.0)$ & $0(0.0)$ & $9(8.0)$ & $7(5.4)$ & $1(0.8)$ & 7.2 & 4.6 \\
\hline Nausea & $4(2.2)$ & $4(4.2)$ & $9(8.0)$ & $11(8.5)$ & $4(3.3)$ & 4.7 & 5.2 \\
\hline$\overline{\text { Anxiety }}$ & $3(1.7)$ & $2(2.1)$ & $11(9.7)$ & $14(10.9)$ & $7(5.7)$ & 4.0 & 5.2 \\
\hline $\begin{array}{l}\text { Salivary } \\
\text { hypersecretion }\end{array}$ & $3(1.7)$ & $0(0.0)$ & $6(5.3)$ & $5(3.9)$ & $0(0.0)$ & 3.6 & 2.2 \\
\hline Akathisia & $8(4.5)$ & $3(3.2)$ & $5(4.4)$ & $6(4.7)$ & $1(0.8)$ & 2.3 & 2.6 \\
\hline Dizziness & $8(4.5)$ & $3(3.2)$ & $5(4.4)$ & $8(6.2)$ & $3(2.5)$ & $\mathrm{NA}^{\dagger}$ & 2.4 \\
\hline $\begin{array}{l}\text { Nasal } \\
\text { congestion }\end{array}$ & $1(0.6)$ & $0(0.0)$ & $4(3.5)$ & $7(5.4)$ & $3(2.5)$ & $\mathrm{NA}^{+}$ & 2.3 \\
\hline \multicolumn{8}{|c|}{$\begin{array}{l}\text { *If } \Delta \text { ([risperidone-placebo (RIS)] - [paliperidone-placebo (PALI)]) } \geq 2 \% \text {. If the placebo rate for any adverse event (AE) was greater than for active treatment, then } \\
\text { active treatment minus placebo was set equal to } 0 \text {. }\end{array}$} \\
\hline \multicolumn{8}{|c|}{${ }^{+}$Signifies placebo-adjusted AEs $<2 \%$} \\
\hline \multicolumn{8}{|c|}{ All AEs were those reported by week 6.} \\
\hline
\end{tabular}

A literature search (through December 31, 2009) identified 4 additional placebo-controlled studies of paliperidone ER monotherapy and 5 additional placebocontrolled studies of risperidone monotherapy that were not included in the present analysis. Individual patientlevel data were available for the 4 paliperidone ER studies and for 1 of the risperidone studies, but their designs were inappropriate for inclusion. The study by Tzimos et al examined subjects that were $>65$ years old [15]. The study by Luthringer et al was 2 weeks in duration and focused on the effect of paliperidone ER on sleep measurements [16]. The study by Kramer et al focused on relapse prevention; it included subjects who were initially stabilized on paliperidone ER for 8 weeks prior to the double-blind phase [17]. The paliperidone ER study by Canuso et al and the risperidone study by Potkin et al evaluated monotherapy for only 2 weeks, followed by a 4-week additive therapy phase during which additional psychotropics could be administered $[18,19]$. For the remaining risperidone studies [20-23], individual patient-level data for the propensity score analysis were not available.

Because the propensity score matching approach does not include all of the subjects from the original studies, differences can arise in the patient populations. The nonrandomized design of this study can limit the clinical interpretation of these results. One example is the significant difference in placebo completion rates$36.8 \%$ for the placebo (PALI) group vs $51.6 \%$ for the placebo (RIS) group-which influenced the placeboadjusted response rate of the risperidone groups. Additionally, the risperidone $2-4 \mathrm{mg} /$ day did not separate from placebo on PANSS total score change and therefore may not have been a valid active risperidone comparison for paliperidone ER 6-12 mg/day. However, the original risperidone study found that the $2 \mathrm{mg} /$ day dose was superior to placebo [12]. In fact, the p value (0.052) in this analysis only narrowly missed statistical significance. As a result, the significant differences in PANSS total scores between the paliperidone ER 6-12 $\mathrm{mg} /$ day and risperidone $2-4 \mathrm{mg}$ /day groups will need to be confirmed using randomized controlled studies to establish their clinical relevance. Additionally, the dropout rates in studies need to be considered when interpreting the efficacy findings. Although it is easy to implement the LOCF methodology, this method may not be the most robust approach in estimating the true treatment differences and controlling type I error rates. Also, in this 
particular analysis these trials were of a short duration, as is generally found with placebo-controlled trials in schizophrenia, and long-term effectiveness of these dosage groups could therefore not be evaluated.

Comparison of risperidone and paliperidone ER prolactin levels was limited by the availability of data and differences in the timing of specimen collection and trial duration. Prolactin specimens were collected in only 1 risperidone study (RIS-INT-3) vs all 3 paliperidone ER trials. The blood samples in the paliperidone ER studies were obtained at $\mathrm{T}_{\max }$, whereas the timing of blood draws was not specified in the risperidone study. Further, prolactin data for risperidone were available only at baseline and at week 8 end point, prohibiting comparisons at the same time point (week 6) between risperidone and paliperidone ER. However, an analysis from a separate 6-day phase I study in stable subjects with schizophrenia found similar prolactin pharmacokinetic profiles $\left(C_{\max }\right.$ and $\left.A U C\right)$ when subjects received the highest recommended dose of paliperidone ER (12 $\mathrm{mg} /$ day) compared with an average dose of risperidone (4 mg/day) [2]. Finally, our ability to assess EPS severity was limited because the studies did not use the same movement disorder rating scales. With the exception of spontaneously reported akathisia, EPS-related AEs (parkinsonism, dystonia, tremor, hypertonia and hypokinesia) did not meet the criteria specified in the Methods section (AE differential $\geq 2 \%$ ), which identified notable differences in $\mathrm{AE}$ rates between paliperidone ER and risperidone.

\section{Conclusions}

In the absence of prospective, randomized, head-to-head clinical trials, a statistical comparison using propensity score matching of pooled data may be a feasible and informative technique to provide a preliminary comparison of 2 medications. This analysis suggests that paliperidone ER 6-12 $\mathrm{mg} /$ day may be as efficacious as risperidone 4-6 $\mathrm{mg} /$ day and more efficacious than risperidone $2-4 \mathrm{mg} /$ day. $\mathrm{AE}$-adjusted incidence rates found differences between the treatment groups that may be relevant for individual patients. As this was an indirect analysis of these 2 medications, randomized, well-controlled, head-to-head studies are required to confirm these findings.

\section{Acknowledgements}

The authors wish to acknowledge the writing and editing assistance provided by Matthew Grzywacz, PhD, Mariana Ovnic, PhD, and ApotheCom, LLC (funding supported by Ortho-McNeil Janssen Scientific Affairs, LLC, Titusville, NJ, USA) in the development and submission of this manuscript. Supported by Ortho-McNeil Janssen Scientific Affairs, LLC.

\section{Author details}

'Johnson \& Johnson Pharmaceutical Research and Development, LLC, Titusville, New Jersey, USA. ${ }^{2}$ Ortho-McNeil Janssen Scientific Affairs, LLC,
Titusville, New Jersey, USA. ${ }^{3}$ New York University, New York, New York, USA. ${ }^{4}$ SUNY Downstate Medical Center, Brooklyn, New York, USA.

\section{Authors' contributions}

IT, CB and CC contributed to the conception and design, acquisition of data, analysis and interpretation of data and drafting of the manuscript and its critical revision for important intellectual content. JPL and NS were involved in the interpretation of data, and critical drafting and revising of the manuscript for important intellectual content. All authors read and approved the final manuscript.

\section{Competing interests}

Mr. Turkoz and Dr. Canuso are full-time employees of Johnson \& Johnson Pharmaceutical Research and Development, LLC, and are Johnson \& Johnson stockholders. Dr. Bossie is a full-time employee of Ortho-McNeil Janssen Scientific Affairs, the company that funded the research, and is a Johnson \& Johnson stockholder. Dr. Lindenmayer has received grant/research support from Janssen, Eli Lilly and Company, AstraZeneca, Johnson \& Johnson, Pfizer, Bristol-Myers Squibb, Otsuka and Dainippon Sumitomo; and has served as a consultant to Janssen, Eli Lilly and Company and Schering-Plough. Dr. Schooler has received grant/research support from AstraZeneca, Bristol-Myers Squibb, Eli Lilly and Company, H. A. Lundbeck, Ortho-McNeil Janssen and Pfizer Inc; and has served as a consultant/advisory board member/speaker for Dainippon Sumitomo, Eli Lilly and Company, H. A. Lundbeck, Organon, OrthoMcNeil Janssen and Schering-Plough.

Received: 17 November 2009 Accepted: 7 February 2011 Published: 7 February 2011

\section{References}

1. Conley R, Gupta SK, Sathyan G: Clinical spectrum of the osmoticcontrolled release oral delivery system (OROS), an advanced oral delivery form. Curr Med Res Opin 2006, 22:1879-1892.

2. Berwaerts J, Cleton A, Rossenu S, Talluri K, Remmerie B, Janssens L, Boom S, Kramer M, Eerdekens M: A comparison of serum prolactin concentrations after administration of paliperidone extended-release and risperidone tablets in patients with schizophrenia. J Psychopharmacol 2010, 24(7):1011-8.

3. Berwaerts J, Cleton A, Herben V, van de Vliet I, Chang I, van Hoek P, Eerdekens M: The effects of paroxetine on the pharmacokinetics of paliperidone extended-release tablets. Pharmacopsychiatry 2009, 42:158-163.

4. Vermeir M, Boom S, Naessens I, Talluri K, Eerdekens M: Absorption, metabolism and excretion of a single oral dose of $1 \mathrm{mg}$ paliperidone in a population of five healthy male subjects. Eur Neuropsychopharmacol 2005, 15(Suppl 3):S648.

5. Marder SR, Meibach RC: Risperidone in the treatment of schizophrenia. Am J Psychiatry 1994, 151:825-835.

6. Chouinard G, Jones B, Remington G, Bloom D, Addington D, MacEwan GW, Labelle A, Beauclair L, Arnott W: A Canadian multicenter placebocontrolled study of fixed doses of risperidone and haloperidol in the treatment of chronic schizophrenic patients. J Clin Psychopharmacol 1993, 13:25-40.

7. Kane J, Canas F, Kramer M, Ford L, Gassmann-Mayer C, Lim P, Eerdekens M: Treatment of schizophrenia with paliperidone extended-release tablets: a 6-week placebo-controlled trial. Schizophr Res 2007, 90:147-161.

8. Marder SR, Kramer M, Ford L, Eerdekens E, Lim P, Eerdekens M, Lowy A: Efficacy and safety of paliperidone extended-release tablets: results of a 6-week, randomized, placebo-controlled study. Biol Psychiatry 2007, 62:1363-1370

9. Davidson M, Emsley R, Kramer M, Ford L, Pan G, Lim P, Eerdekens M: Efficacy, safety and early response of paliperidone extended-release tablets (paliperidone ER): results of a 6-week, randomized, placebocontrolled study. Schizophr Res 2007, 93:117-130.

10. Rosenbaum PR, Rubin DR: The central role of the propensity score in observational studies for causal effects. Biometrika 1983, 70:41-55.

11. Kay SR, Fiszbein A, Opler LA: The positive and negative syndrome scale (PANSS) for schizophrenia. Schizophr Bull 1987, 13:261-276.

12. Marder SR, Davis JM, Chouinard G: The effects of risperidone on the five dimensions of schizophrenia derived by factor analysis: combined results of the North American trials. J Clin Psychiatry 1997, 58:538-546. 
13. Guy W: Clinical global impressions. ECDEU Assessment Manual for Psychopharmacology. Revised, 1976 edition Rockville, Maryland: U.S. Department of Health and Human Services; 1976, 218-222.

14. Joffe MM, Rosenbaum PR: Invited commentary: propensity scores. Am J Epidemiol 1999, 150:327-333.

15. Tzimos A, Samokhvalov V, Kramer M, Ford L, Gassmann-Mayer C, Lim P, Eerdekens M: Safety and tolerability of oral paliperidone extendedrelease tablets in elderly patients with schizophrenia: a double-blind, placebo-controlled study with six-month open-label extension. Am J Geriatr Psychiatry 2008, 16(1):31-43.

16. Luthringer R, Staner L, Noel N, Muzet M, Gassmann-Mayer C, Talluri K, Cleton A, Eerdekens M, Battisti WP, Palumbo JM: A double-blind, placebocontrolled, randomized study evaluating the effect of paliperidone extended-release tablets on sleep architecture in patients with schizophrenia. Int Clin Psychopharmacol 2007, 22(5):299-308.

17. Kramer M, Simpson G, Maciulis V, Kushner S, Vijapurkar U, Lim P, Eerdekens M: Paliperidone extended-release tablets for prevention of symptom recurrence in patients with schizophrenia: a randomized, double-blind, placebo-controlled study. I Clin Psychopharmacol 2007, 27(1):6-14

18. Canuso CM, Dirks B, Carothers J, Kosik-Gonzalez C, Bossie CA, Zhu Y, Damaraju CV, Kalali AH, Mahmoud R: Randomized, double-blind, placebocontrolled study of paliperidone extended-release and quetiapine in inpatients with recently exacerbated schizophrenia. Am J Psychiatry 2009, 166(6):691-701.

19. Potkin SG, Gharabawi GM, Greenspan AJ, Mahmoud R, Kosik-Gonzalez C, Rupnow MF, Bossie CA, Davidson M, Burtea V, Zhu Y, Trivedi JK: A doubleblind comparison of risperidone, quetiapine and placebo in patients with schizophrenia experiencing an acute exacerbation requiring hospitalization. Schizophr Res 2006, 85(1-3):254-265.

20. Casey DE, Sands EE, Heisterberg J, Yang HM: Efficacy and safety of bifeprunox in patients with an acute exacerbation of schizophrenia: results from a randomized, double-blind, placebo-controlled, multicenter, dose-finding study. Psychopharmacology (Berl) 2008, 200(3):317-331.

21. Potkin $S G$, Cohen $M$, Panagides J: Efficacy and tolerability of asenapine in acute schizophrenia: a placebo- and risperidone-controlled trial. $J$ Clin Psychiatry 2007, 68(10):1492-1500

22. Potkin SG, Saha AR, Kujawa MJ, Carson WH, Ali M, Stock E, Stringfellow J, Ingenito G, Marder SR: Aripiprazole, an antipsychotic with a novel mechanism of action, and risperidone vs placebo in patients with schizophrenia and schizoaffective disorder. Arch Gen Psychiatry 2003, 60(7):681-690.

23. Borison RL, Pathiraja AP, Diamond Bl, Meibach RC: Risperidone: clinical safety and efficacy in schizophrenia. Psychopharmacol Bull 1992, 28(2):213-218.

Pre-publication history

The pre-publication history for this paper can be accessed here: http://www.biomedcentral.com/1471-244X/11/21/prepub

doi:10.1186/1471-244X-11-21

Cite this article as: Turkoz et al.: Paliperidone ER and oral risperidone in patients with schizophrenia: a comparative database analysis. BMC Psychiatry 2011 11:21.

\section{Submit your next manuscript to BioMed Central and take full advantage of:}

- Convenient online submission

- Thorough peer review

- No space constraints or color figure charges

- Immediate publication on acceptance

- Inclusion in PubMed, CAS, Scopus and Google Scholar

- Research which is freely available for redistribution 